\title{
Diurnal Precipitation Regimes in the Global Tropics*
}

\author{
KAZUYOSHI KIKUCHI AND BIN WANG ${ }^{+}$ \\ Department of Meteorology, and International Pacific Research Center, University of Hawaii at Manoa, Honolulu, Hawaii
}

(Manuscript received 18 May 2007, in final form 17 September 2007)

\begin{abstract}
Diurnal variations of the global tropical precipitation are documented by using two complementary Tropical Rainfall Measuring Mission (TRMM) datasets (3B42 and 3G68) for 1998-2006 in an attempt to provide a unified view of the diurnal cycle and a metric for evaluating numerical model performance. The 3B42 data have better spatial coverage; the 3G68 data offer more accurate diurnal phase information. The first and second empirical orthogonal function (EOF) modes represent the diurnal cycle and account for $89 \%$ of the total variance in $3 \mathrm{~B} 42$. The third and fourth EOF modes, which account for $10 \%$ of the total variance, represent the semidiurnal cycle. Both datasets yield consistent spatial structures and temporal evolution, but they have different advantages: the patterns derived from 3B42 exhibit less noise, while $3 \mathrm{G} 68$ yields an arguably more accurate diurnal phase. The diurnal phase derived from 3G68 systematically leads 3B42 by about $3 \mathrm{~h}$.

Three tropical diurnal cycle regimes (oceanic, continental, and coastal) are identified according to the amplitude, peak time, and phase propagation characteristics of the diurnal precipitation. The oceanic regime is characterized by moderate amplitude and an early morning peak [0600-0900 Local Solar Time (LST)], found primarily in the oceanic convergence zones in the Pacific, Atlantic, and Indian Oceans. In contrast, the continental regime features a large amplitude and an afternoon peak (1500-1800 LST), which is particularly pronounced in South America and equatorial Africa near Lake Victoria. Both the oceanic and continental regimes show little spatial phase propagation. The coastal regime, however, shows not only large amplitude but also prominent phase propagation. Two subregimes can also be recognized, often concurring along the same land-sea boundary. The seaside coastal regime is characterized by offshore phase propagation, with peaks occurring from late evening to noon of the next day (2100-1200 LST), whereas the landside coastal regime has landward phase propagation with peaks occurring from noon to evening (1200 2100 LST). The coastal regime is prominent along the land-sea boundaries of the Maritime Continent, the Indian subcontinent, northern Australia, the west coast of America extending from Mexico to Ecuador, the west coast of equatorial Africa, and Northeast Brazil. Note that the amplitude of the diurnal cycle is dependent on season, but the diurnal phase characteristics are not. The underlying mechanism suggested by this analysis, especially over the coastal areas, is also discussed.
\end{abstract}

\section{Introduction}

The diurnal cycle is one of the predominant components of atmospheric variations. Like the seasonal

\footnotetext{
* School of Ocean and Earth Science and Technology Contribution Number 7449 and International Pacific Research Center Contribution Number 491.

+ Additional affiliation: College of Physical and Environmental Oceanography, Ocean University of China, Qingdao, China.

Corresponding author address: Bin Wang, International Pacific Research Center, University of Hawaii at Manoa, 1680 East-West Rd., POST Bldg. 401, Honolulu, HI 96822.

E-mail: wangbin@hawaii.edu
}

cycle, it is a manifestation of the atmosphere-oceanland-cryosphere system's response to solar radiation. Thus, the diurnal cycle provides a good opportunity for testing our understanding and modeling of the fundamental physical processes, including cloud physics, cloud-radiation interactions, air-sea and air-land interactions, and small- and large-scale interactions.

A typical picture of diurnal cycle of tropical deep convection and associated precipitation derived from the previous observational studies is as follows: the amplitude of the diurnal cycle over land is much larger than that over ocean. The summer hemisphere has larger amplitude of diurnal cycle than its winter counterpart. The maximum precipitation tends to occur in the late afternoon/early evening over land and in the early morning over ocean. These results were obtained 
from both in situ observations (Ray 1928; Cook 1939; Kraus 1963; Andersson 1970; Wallace 1975; Gray and Jacobson 1977; McGarry and Reed 1978; Kousky 1980; Albright et al. 1981; Hamilton 1981) and satellite observations (Albright et al. 1985; Salby et al. 1991; Hendon and Woodberry 1993; Chang et al. 1995; Garreaud and Wallace 1997; Yang and Slingo 2001; Tian et al. 2004).

The reality, however, is more complex. Some studies (Ramage 1964; Wallace 1975) noted that a precipitation maximum tends to occur during nighttime even over land. Also, an afternoon precipitation maximum can be found even over oceans, such as the eastern tropical Atlantic (Gray and Jacobson 1977; Reed and Jaffe 1981; Albright et al. 1985), the South Pacific convergence zone (SPCZ; Albright et al. 1985; Sui et al. 1997), and the central and eastern tropical Pacific (Augustine 1984).

Complex orography, land-sea breezes, and mountainvalley breezes may be responsible for causing different kinds of diurnal cycle in various regions. Different behaviors of the diurnal cycle have been reported in coastal regions. Yang and Slingo (2001) suggested that coherent diurnal convective variations propagate away from the coast of the Indonesian islands, southwestward away from the Mexican coast, and down the Bay of Bengal and off the West African coast. Similar offcoast propagation was observed over Sumatra Island (Mori et al. 2004). On the other hand, it was also documented that a precipitation peak phase propagates from the coastline inland over Sumatra Island (Mori et al. 2004) and over Brazil (Garreaud and Wallace 1997). In addition to land-sea contrast, topography adds complex features to the diurnal cycle. Tian et al. (2005) and Jiang et al. (2006) have recently shown that eastward phase propagation of diurnal precipitation from the Rocky Mountains to the Great Plains occurred in late afternoon to early morning.

Because of the complexities of diurnal cycle, no unified view has been obtained so far in the global tropics. The purpose of this study is to construct a reference of the climatological diurnal precipitation in the global tropics using nine years of Tropical Rainfall Measuring Mission (TRMM) data and empirical orthogonal function (EOF) analysis. This work will not only provide a metric for evaluating global numerical models' performance but also broaden our knowledge and shed some light on the mechanism at work.

The TRMM data provide us this opportunity to study the variation of precipitation. Most previous studies that documented diurnal precipitation or cloudiness in global tropics employed infrared (IR) data, which are taken by geostationary and/or polar-orbiting satel- lites (Salby et al. 1991; Hendon and Woodberry 1993; Janowiak et al. 1994; Yang and Slingo 2001; Smith and Rutan 2003). The IR-based precipitation estimate, however, has some problems primarily due to the uncertainty in conversion of IR radiance to precipitation. In general, precipitation can be estimated by relating it to deep convective clouds, which can be detected from IR radiance; thus, the estimate depends on selecting a threshold temperature (Tian et al. 2004). Some studies report that IR-based precipitation estimates tend to delay by about 3-4 h compared with those measured by ground-based radar or in situ rain gauge data, especially in the region of high anvil clouds (Houze and Betts 1981; Kubota and Nitta 2001; Ohsawa et al. 2001), probably because of the contamination of nonprecipitating cirrus anvil clouds which develop after the development of deep convective clouds. In addition, at fine time or spatial scales, which are necessary for a detailed description of diurnal cycle, the IR is poorly correlated with precipitation (Arkin and Meisner 1987). In contrast, the TRMM satellite launched in late 1997 is the first satellite that has an onboard Precipitation Radar (PR) observing raindrops directly (see Simpson et al. 1996 and Kummerow et al. 2000 for detailed descriptions of the TRMM satellite).

Some efforts have been made to elucidate the characteristics of global diurnal precipitation utilizing the TRMM data. Takayabu (2002) investigated the mean feature of diurnal precipitation averaged over all land areas and all ocean areas within the narrow equatorial band $\left(10^{\circ} \mathrm{N}-10^{\circ} \mathrm{S}\right)$ using two years of TRMM PR data. Sorooshian et al. (2002) described the diurnal variability of precipitation over a large tropical and subtropical region using blended data that combine the information from three geostationary satellites and the TRMM satellite over one year. Nesbitt and Zipser (2003) used three years of PR and TRMM Microwave Image (TMI) data to focus on precipitation features of the diurnal cycle based on a classification of rainfall system type. Bowman et al. (2005) analyzed data from rain gauges and TRMM measurements over six years to study the diurnal cycle in precipitation in an attempt to establish confidence limits on the amplitude and phase of the diurnal cycle measured by TRMM. Yang and Smith (2006) analyzed the behavior of diurnal variability in precipitation using TRMM data for 1998 and discussed the underlying forcing mechanisms.

In spite of all the efforts mentioned above, our knowledge based on the TRMM data remains limited because of the uncertainties caused by insufficient PR sampling. Some of the previous studies (Takayabu 2002; Nesbitt and Zipser 2003; Bowman et al. 2005) smoothed the data in order to reduce the sampling un- 
certainty. The results of Sorooshian et al. (2002) retained high spatial resolution, but were based on only one year's data. Since the diurnal precipitation has large spatial variability (Yang and Slingo 2001; Mori et al. 2004), fine spatial resolution is necessary. The entire TRMM data record is nine years long, which may not be long enough for PR observation to obtain a robust climatological diurnal precipitation on account of its narrow swath width. To reduce the uncertainty stemming from insufficient sampling, we use two kinds of TRMM-related datasets (3B42 and 3G68; see next section) to obtain complementary information.

\section{Data and methodology}

Two kinds of TRMM datasets are used in this study. One of them is the TRMM 3B42 version 6 that provides high spatial $\left(0.25^{\circ} \times 0.25^{\circ}\right)$ and high temporal $(3 \mathrm{~h})$ precipitation data. These data are created by blending passive microwave data collected by the TMI, the Special Sensor Microwave Imager (SSM/I), the Advanced Microwave Scanning Radiometer for Earth Observing System (AMSR-E), the Advanced Microwave Sounding Unit B (AMSU-B), and the IR data collected by the international constellation of geosynchronous earth orbit (GEO) based on calibration by the precipitation estimate of the TMI-PR combined algorithm. A simple approach was applied to combine the microwave and IR estimates: the physically based combined microwave estimates are taken "as is" where available, and the remaining grid boxes are filled with microwavecalibrated IR estimates (Huffman et al. 2007). The final product is obtained by rescaling it in reference to rain gauge data on a monthly time scale.

The other dataset is TRMM 3G68 version 6 (information about this data can be found at ftp://trmmopen. gsfc.nasa.gov/pub). Compared to TRMM 3B42, TRMM $3 \mathrm{G} 68$ covers only a small region at a time; however, it is based only on TRMM instruments, which are believed to provide the most reliable precipitation estimate for the tropics from space. It consists of rainfall estimates, number of total pixels, rainy pixels, and percentage of rainfall calculated to be convective from TMI, PR, and the TMI-PR combined algorithm gridded at $0.5^{\circ} \times 0.5^{\circ}$ resolutions for every minute. Hourly data were obtained by applying a 4-h running mean that reduces the spatial variability in the sampling (Negri et al. 2002). In addition, we excluded some data that consist of a very small number of total pixels, because such data might not be reliable. The criteria we used are 30 pixels for TMI and 100 for PR and the TMI-PR combined algorithm, which were subjectively chosen based on the statistical distribution of total pixels. In this paper, we will show the results using data derived from the TMI-PR combined algorithm only (hereafter 3G68); our conclusions would be the same if TMI or PR data were used instead.

Both the 3B42 and the 3G68 data have 9-yr records, from 1998 to 2006. Figure 1a shows the number of samples of the 3G68 at 0000 UTC during the nine years. Since we applied a 4-h running mean, the horizontal variation of the sample numbers is small. In the tropical belt within $15^{\circ}$ of the equator, the number is between 150 and 175 . Note that the sample number represents how many times the TRMM satellite passed over a given location.

Figures $1 \mathrm{~b}$ and $1 \mathrm{c}$ show the climatological annual precipitations derived from the 3B42 and 3G68 data. They are quite consistent in terms of amplitude and pattern, although the 3G68 data seem somewhat noisier because of its smaller sample size.

EOF analysis was used to derive a unified global picture that may help delineate diurnal regimes and facilitate validation of the numerical models. The EOF analysis (Lorenz 1956) is capable of capturing both stationary oscillations such as the Arctic Oscillation (AO; e.g., Thompson and Wallace 1998) and transient oscillations such as the Madden-Julian oscillation (MJO; e.g., Knutson and Weickmann 1987). Previous studies usually described the diurnal precipitation in terms of its amplitude and the phase of the first harmonic of the diurnal cycle (Yang and Slingo 2001; Nesbitt and Zipser 2003; Bowman et al. 2005). That kind of analysis is straightforward, but sometimes it may not yield the comprehensive behavior of the diurnal cycle.

Local solar time (LST), instead of coordinated universal time (UTC), was used to give a clearer picture of the diurnal distribution of precipitation. The UTC is converted to LST based on the longitudinal distance between each grid point and $0^{\circ}$. Then Fourier interpolation is applied to obtain the LST precipitation at given times and at each grid point so that the data at each grid point represent its local time. Note that in our EOF calculation, horizontal resolution is reduced to $1.5^{\circ}$ for computational efficiency without any spatial smoothing. The essential features remain unchanged when using a resolution of $2.0^{\circ}$ or $2.5^{\circ}$.

\section{Seasonal variation of global diurnal precipitation}

To measure the amplitude of diurnal precipitation, we introduce diurnal range (DR), which is defined as the climatological daily maximum precipitation minus daily minimum precipitation. Figure 2 shows horizontal distribution of the DR for annual, June-August (JJA), and December-February (DJF) means. Note that the 
(a) No. of samples of $3 \mathrm{G} 68$ at $00 \mathrm{Z}$

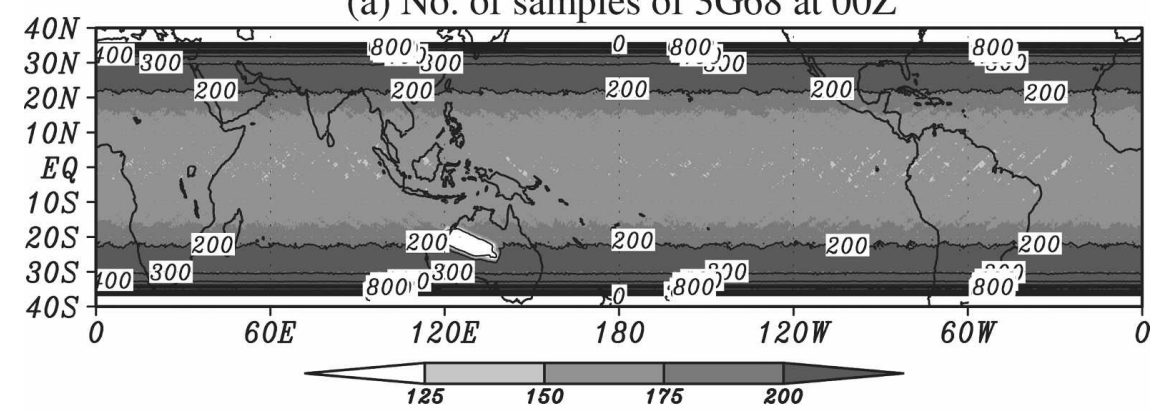

(b) 3B42

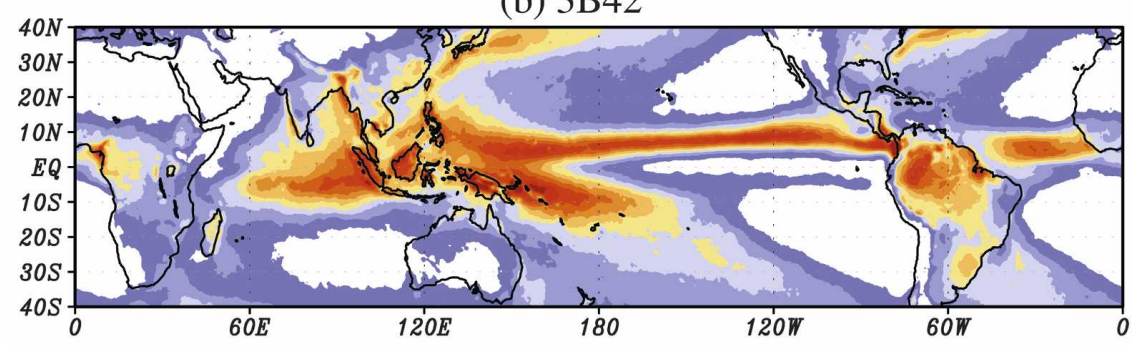

(c) 3G68 PR-TMI combined

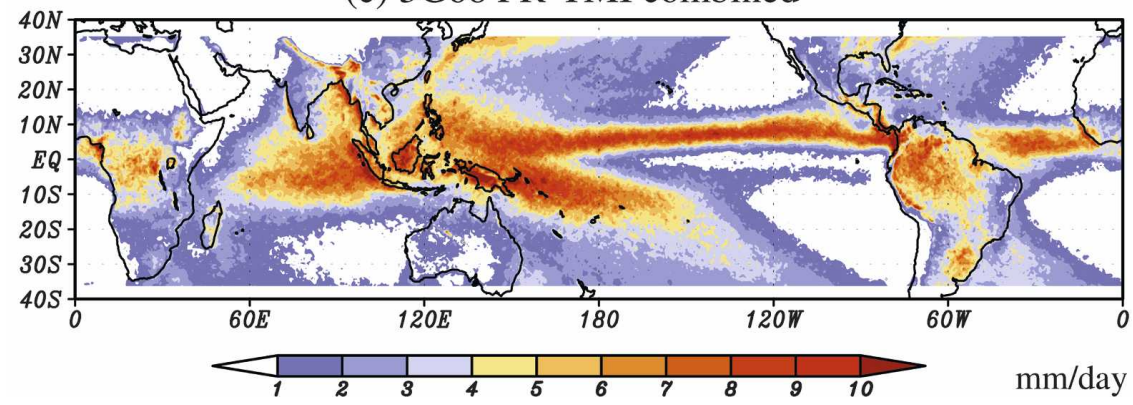

FIG. 1. (a) Distribution of the sample size of $3 \mathrm{G} 68$ at 0000 UTC; (b) climatological annual precipitation derived from TRMM 3B42 data from 1998 to 2006; (c) same as (b) but derived from 3G68 data. The units in (b) and (c) are $\mathrm{mm} \mathrm{day}^{-1}$. The horizontal resolution of the data used for analysis is $0.5^{\circ} \times 0.5^{\circ}$.

DR is about two times larger than the diurnal amplitudes found in previous studies (e.g., Yang and Slingo 2001; Tian et al. 2004). This discrepancy is expected, given the difference of their definitions, and suggests that our results are in fact consistent with their previous results. As suggested by the previous studies, the DR patterns (Fig. 2a) essentially follow the distributions of the climatological precipitation amount (Fig. 1b) but have clearer land-sea contrast. Basically, the DR is much larger over/near land and in the presence of steep topography. Some ocean areas adjacent to continents have relatively large DR, such as the Indonesian Maritime Continent, the Bay of Bengal, and the areas off the west coast of America extending from Mexico to Ecuador and off the west coast of Africa extending from Senegal to Angola. This suggests that the diurnal precipitation spread out from coastal land to its adja- cent ocean, confirming the results of Yang and Slingo (2001).

Since the major cause of diurnal precipitation is solar insolation, the magnitude of the DR is greatly influenced by both latitude and season. In the equatorial band (roughly within $10^{\circ}$ of the equator), the annual mean reflects both JJA and DJF means in terms of magnitude (Fig. 2). In contrast, in the subtropical area ( $10^{\circ}$ away from the equator), seasonal variation of the DR is considerably larger and dominated by local summer season DR.

How is the diurnal precipitation modified by seasonal march? Fig. 3 shows the results of the first two EOFs for JJA and DJF, respectively. The amplitude of the EOFs reflects seasonal variation of the DR. However, in the tropics, the temporal evolution and the corresponding spatial patterns of $\mathrm{EOF}_{1}$ and $\mathrm{EOF}_{2}$ do not 
(a) Annual mean

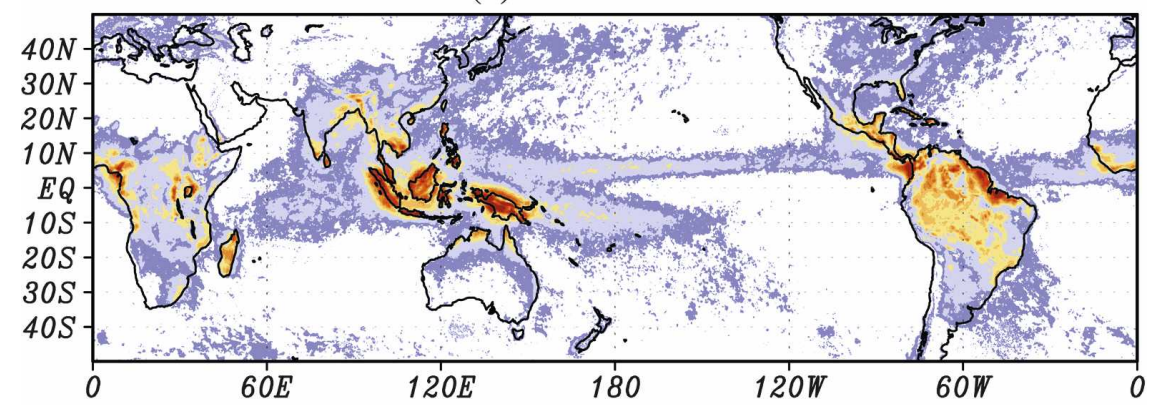

(b) JJA mean

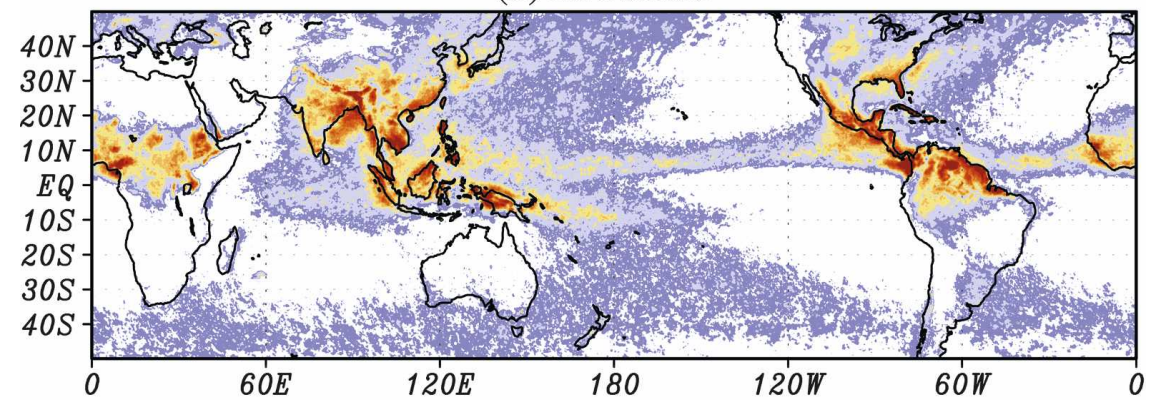

(c) DJF mean

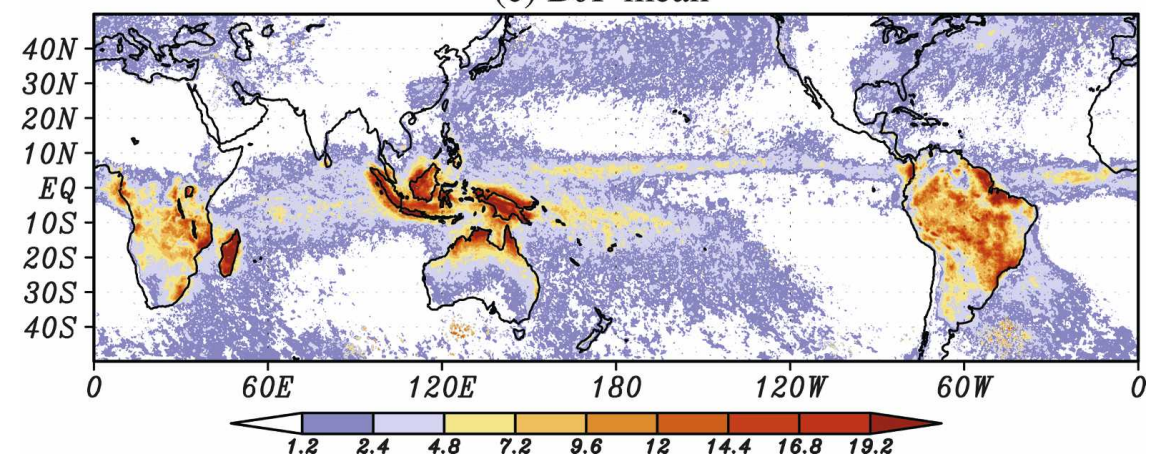

FIG. 2. Diurnal range $\left(\mathrm{mm} \mathrm{day}^{-1}\right)$ derived from $3 \mathrm{~B} 42$ data for (a) annual mean, (b) JJA mean, and (c) DJF mean for the period 1998-2006. Diurnal range is defined as climatological daily maximum precipitation minus daily minimum precipitation. The horizontal resolution is $0.25^{\circ} \times 0.25^{\circ}$.

seem to be altered by season. For instance, in the equatorial region within $10^{\circ} \mathrm{N}-10^{\circ} \mathrm{S}$, where the seasonal variation of amplitude is relatively small, the positivenegative spatial pattern displays quite consistent features in both seasons. The Maritime Continent has positive (negative) values in $\mathrm{EOF}_{1} \mathrm{~s}\left(\mathrm{EOF}_{2} \mathrm{~s}\right)$ and the surrounding ocean has negative (positive) values in $\mathrm{EOF}_{1} \mathrm{~s}\left(\mathrm{EOF}_{2} \mathrm{~s}\right)$. Similarly, positive values over land and negative values over ocean can be seen around equatorial South America in $\mathrm{EOF}_{1} \mathrm{~s}$. The coincidence between the two seasons can be further found in the same region in $\mathrm{EOF}_{2} \mathrm{~S}$ even with more complex features (e.g., a positive-negative pattern over the west coast of equatorial South America and northeast coast of Brazil). Therefore, we will deal with the annual mean case next, which includes the common characteristics of both JJA and DJF and enables us to discuss the overall characteristics of diurnal precipitation in the tropics.

\section{Diurnal precipitation regimes}

\section{a. Comparison of the results derived from $3 B 42$ and $3 G 68$}

Figure 4 shows the results of the EOF analysis using the annual climatological diurnal precipitation of 3B42. The first two modes alone can explain $62 \%$ and $27 \%$ of the total variance, respectively (Fig. 4a). In applying North's significance test (North et al. 1982), we used a sample size of 50 to calculate the number of independent samples that determine the magnitude of the er- 
(a) 3B42 JJA EOF1 (53\%)

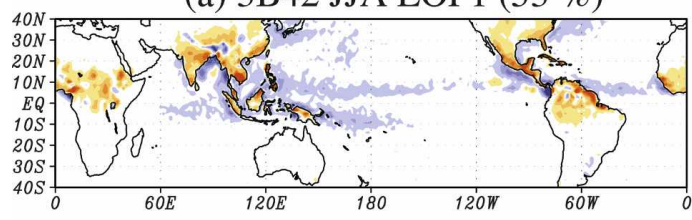

(b) 3B42 JJA EOF2 (28\%)

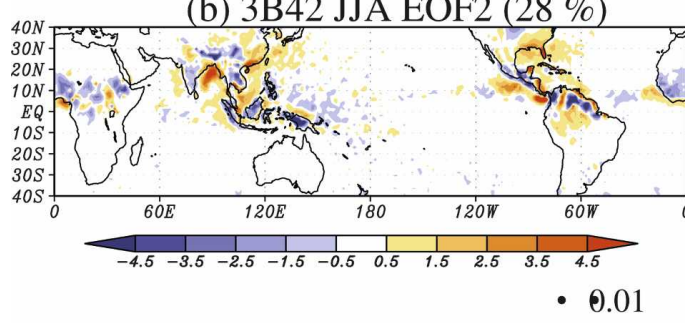

(e) 3B42 JJA PCs

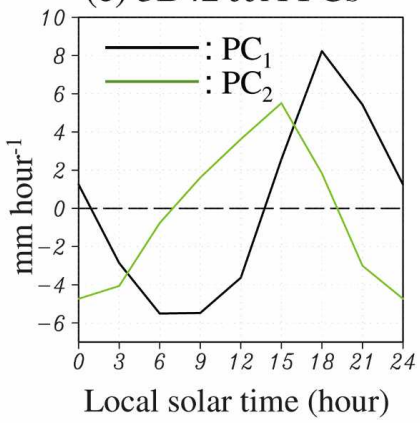

(c) 3B42 DJF EOF1 $(57 \%)$

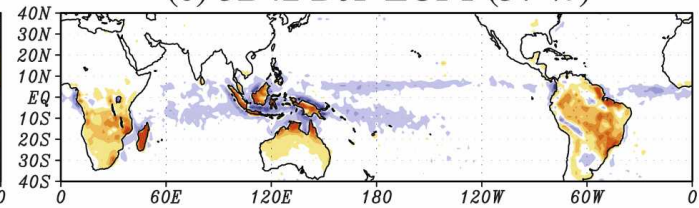

(d) 3B42 DJF EOF2 (23\%)

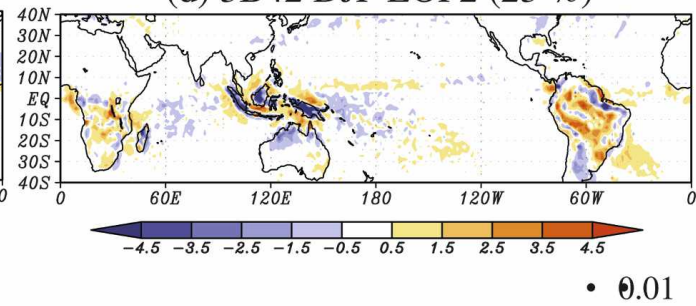

(f) 3B42 DJF PCs

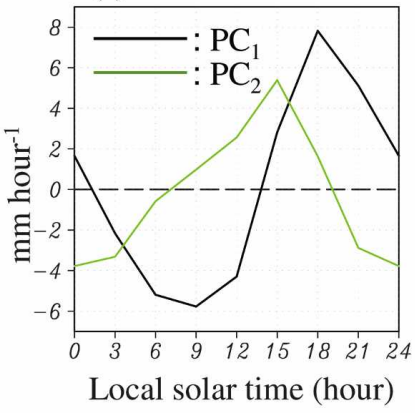

FIG. 3. Seasonal dependence of the diurnal precipitation based on the first two EOF modes. (a) The first and (b) second EOFs for JJA; (c) same as (a), and (d) same as (b), but for DJF; the corresponding PCs for (e) JJA and (f) DJF. The horizontal resolutions of the EOFs are $1.5^{\circ} \times 1.5^{\circ}$.

ror. Because the climatological diurnal precipitation is a composite one, the sample size of 50 is considered to be very conservative compared to the total number of days in nine years (3287). The principal component (PC) time series of the two leading EOFs, namely $\mathrm{PC}_{1}$ and $\mathrm{PC}_{2}$, both have dominant diurnal periodicity (Fig. 4b). EOF $_{1}$ in Fig. 4c represents a universal land-sea contrast, with opposite signs for the land and the ocean. This reflects the difference between land and sea in the atmospheric response to solar radiation forcing. Another universal characteristic is that precipitation maximum tends to occur in the late afternoon (1800 LST) over land areas and in the early morning (0600-0900 LST) over ocean (Fig. 4b). In contrast, $\mathrm{EOF}_{2}$ represents a complementary geographical variation, which is a component deviating from the typical diurnal cycle that

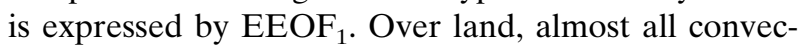
tive regions have negative values, except for the inland of South America, the northeast coast of Brazil, and the inland of Africa around Lake Victoria, where DR is large (Fig. 2). Over ocean, there is a striking contrast between open ocean and ocean in the vicinity of land, namely coastal ocean. There is little amplitude in $\mathrm{EOF}_{2}$ over the open oceans along the intertropical convergence zone (ITCZ) from the Indian Ocean to the Atlantic and the SPCZ. In contrast, the coastal oceans have generally positive $\mathrm{EOF}_{2}$.

Close examination of $\mathrm{EOF}_{1}$ and $\mathrm{EOF}_{2}$ reveals interesting phase propagation over the coastal areas. For example, there is a clear quadrature phase difference over the west coast of Sumatra Island and its adjacent sea between $\mathrm{EOF}_{1}$ and $\mathrm{EOF}_{2}$. After combining $\mathrm{EOF}_{1}$ and $\mathrm{EOF}_{2}$, offshore phase propagation becomes evident there. Similar quadrature phase differences can be seen over the other coastal regions such as the Bay of Bengal and the west coast of South America. We will further examine this phase propagation feature later in section 5 using an extended EOF analysis.

The EOFs from the $3 \mathrm{G} 68$ provide quite consistent features. The first two EOFs account for most of the variation (about $67 \%$; Fig. 5a), and they both have diurnal periods (Fig. 5b). The horizontal patterns of $\mathrm{EOF}_{1}$ and $\mathrm{EOF}_{2}$ contain the same characteristics shown by $3 \mathrm{~B} 42$ dataset but are noisier, especially over ocean. There exists, however, a notable phase lag in their PCs between the EOF results of $3 \mathrm{~B} 42$ and $3 \mathrm{G} 68$. Both $\mathrm{PC}_{1}$ 
(a) eigenvalue spectrum

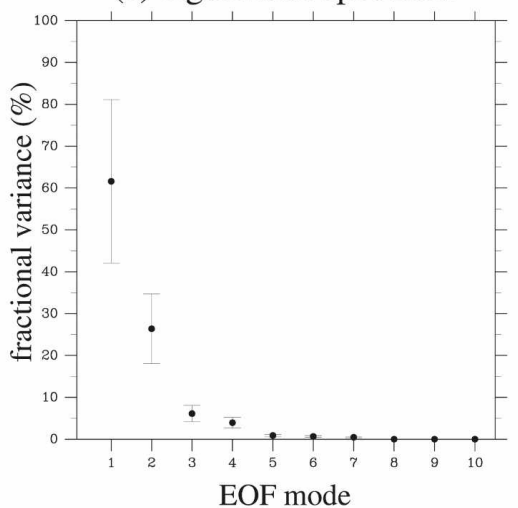

(b) PCs

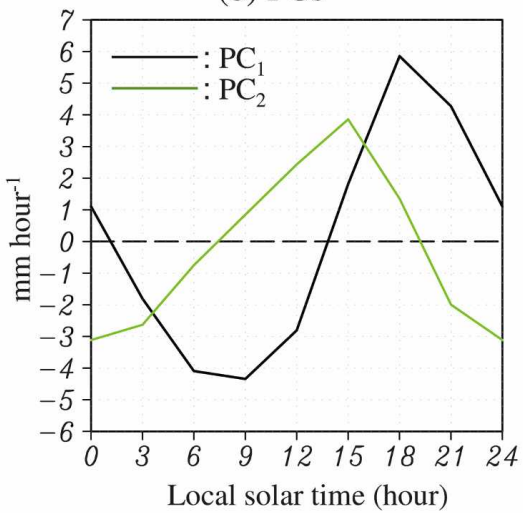

(c) 3B42 EOF1 $(62 \%)$

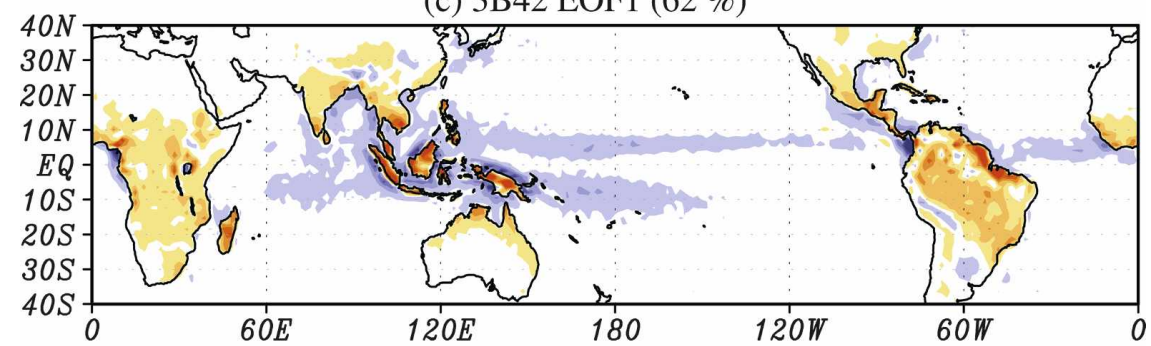

(d) 3B42 EOF2 (27\%)

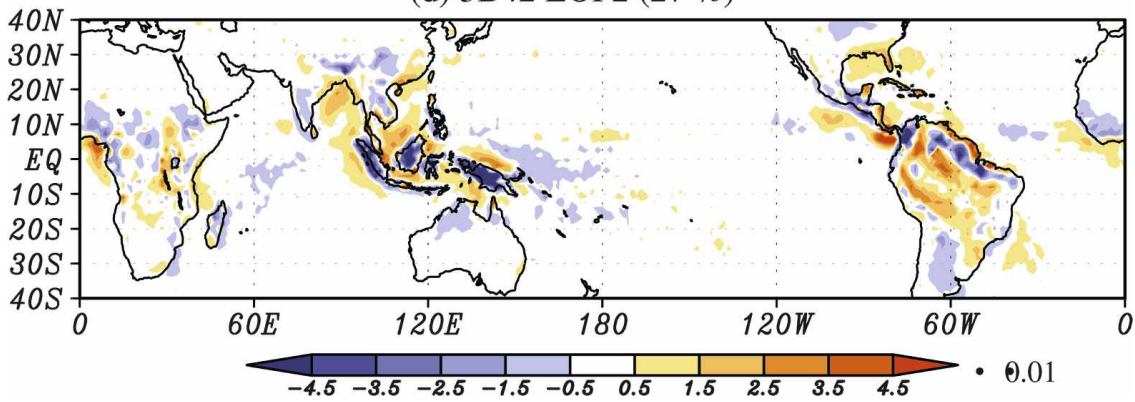

FIG. 4. EOF analysis of the annual mean diurnal cycle derived from precipitation of $3 \mathrm{~B} 42$ for the period of 1998-2006. (a) Eigenvalue spectrum, (b) time series of the $\mathrm{PC}_{1}$ and $\mathrm{PC}_{2}$, and horizontal distribution of (c) $\mathrm{EOF}_{1}$ and (d) $\mathrm{EOF}_{2}$. The horizontal resolution of the EOFs is $1.5^{\circ} \times 1.5^{\circ}$.

and $\mathrm{PC}_{2}$ of $3 \mathrm{G} 68$ lead those of $3 \mathrm{~B} 42$ by about $3 \mathrm{~h}$. This phase lag may be related to the following facts: first, precipitation estimated by IR tends to lag behind in situ observations by about $3 \mathrm{~h}$. Second, a similar but smaller lag (1-2 h) exists between the 3G68 PR-TMI combined precipitation and the 3G68 TMI precipitation in terms of their PCs (not shown). Thus, the temporal phase derived from 3G68 is arguably more reliable. We will therefore adjust the PC time series by three hours (according to the PCs in 3G68) when we interpret results of the $3 \mathrm{~B} 42$ in the discussion throughout the rest of the paper.

The spatial patterns of $\mathrm{EOF}_{1}$ and $\mathrm{EOF}_{2}$ derived from $3 \mathrm{~B} 42$, however, seem more reliable than those from $3 \mathrm{G} 68$. The horizontal patterns of 3B42 show better organized features, probably because the $3 \mathrm{~B} 42$ data are based on samples from multiple platforms and have better spatial resolution. As a result, the contributions of the first two EOFs of 3B42 are larger than those of the $3 \mathrm{G} 68$. Note that the contributions of those EOFs of $3 \mathrm{G} 68$ do not depend on its temporal resolution, since the same result can be obtained when the temporal resolution of the $3 \mathrm{G} 68$ data is reduced to $3 \mathrm{~h}$ just as in the 3B42 data (not shown). Thus, we will rely on 3B42 when we discuss the spatial patterns of the EOFs.

\section{b. Global diurnal precipitation regimes}

Here we document detailed features of global diurnal precipitation according to the choices we have made in section $4 \mathrm{a}$. When we discuss the timing of the occurrence of the maximum precipitation, we determine it by 
(a) Eigenvalue spectrum

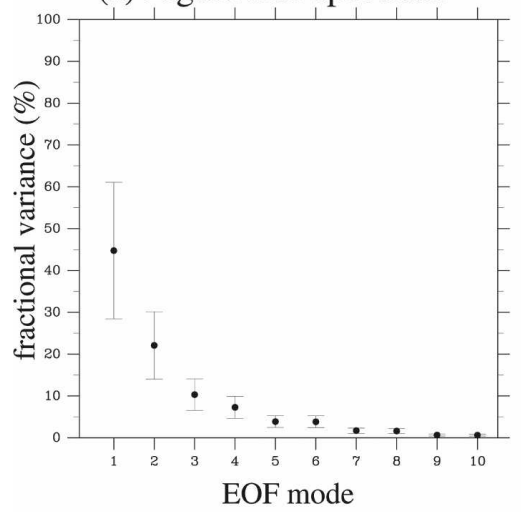

(b) PCs

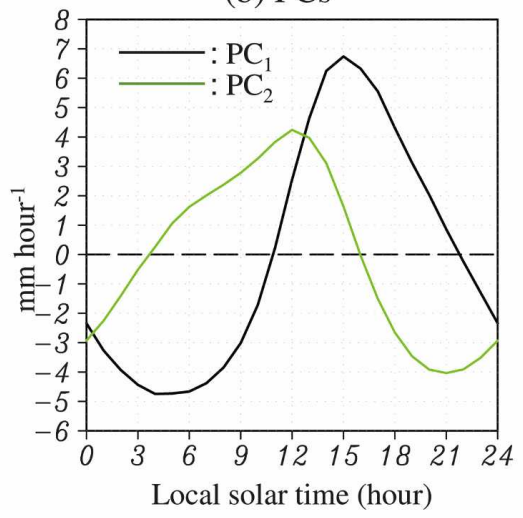

(c) 3G68_combine EOF1 (45\%)

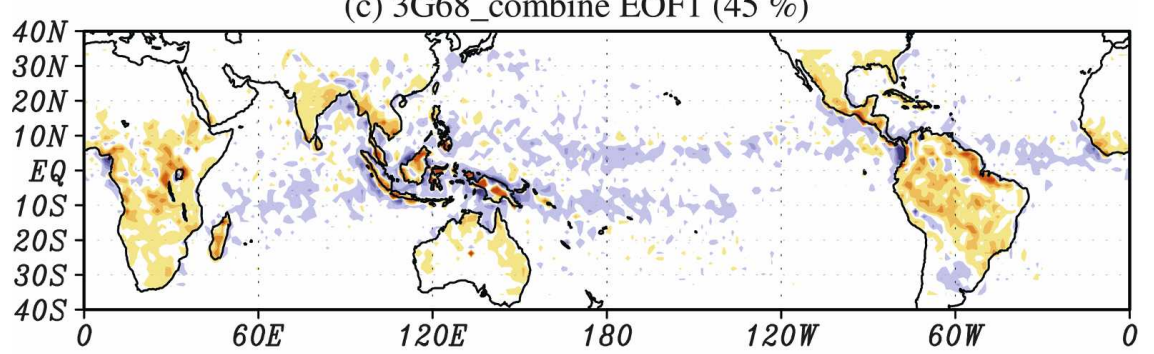

(d) 3G68_combine EOF2 (22\%)

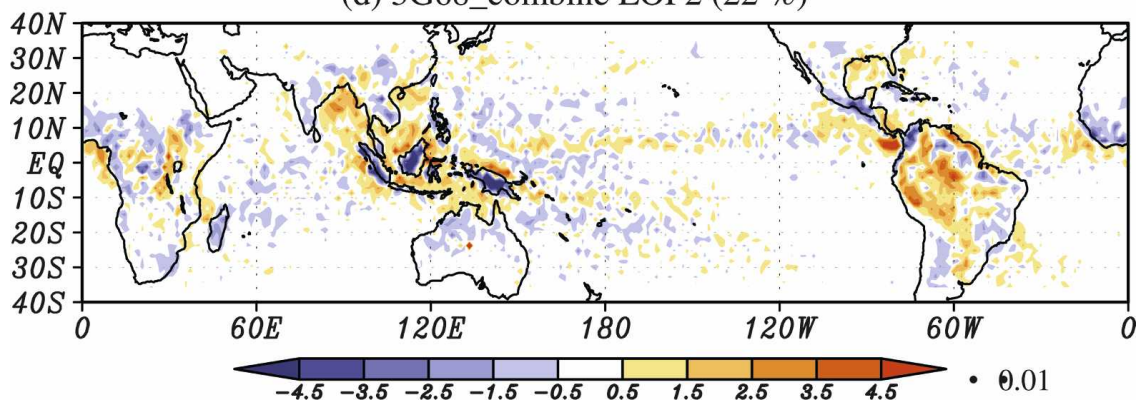

FIG. 5. Same as Fig. 4, but obtained by using $3 \mathrm{G} 68$ data.

adding the first two EOFs. In other words, precipitation variation, which can be accounted for by $\mathrm{EOF}_{1}$ and $\mathrm{EOF}_{2}$, is represented by $\mathrm{EOF}_{1}$ times $\mathrm{PC}_{1}$ plus $\mathrm{EOF}_{2}$ times $\mathrm{PC}_{2}$. As a result, the land and ocean areas can be classified into several regimes based on the EOFs. (i) The oceanic regime, which has a negative $\mathrm{EOF}_{1}$ and a nearly zero $\mathrm{EOF}_{2}$, is primarily found in the ITCZ, SPCZ, and southern Indian Ocean convergence zone. Over the oceanic convergence zones, the diurnal cycle has an early morning peak (0600-0900 LST). (ii) The continental regime, which is particularly pronounced in South America and Africa around Lake Victoria that have positive $\mathrm{EOF}_{1}$ and $\mathrm{EOF}_{2}$, has an afternoon peak (1500-1800 LST) in precipitation. (iii) The coastal regime consisting of the seaside coastal and landside coastal subregimes. (iv) A subset of (iii), the seaside coastal regime has a negative $\mathrm{EOF}_{1}$ and a positive
$\mathrm{EOF}_{2}$ except for some regions over the northeast coast of Brazil, the Yucatan Peninsula, and the east coast of Honduras and Nicaragua, where a positive $\mathrm{EOF}_{2}$ instead of a negative $\mathrm{EOF}_{2}$ appears because of the earlier development of diurnal precipitation there compared to the other regions in the same regime: its maximum precipitation tends to occur from early morning hours to noon (0300-1200 LST). (v) Also a subset of (iii), the landside coastal regime has a positive $\mathrm{EOF}_{1}$ and a negative $\mathrm{EOF}_{2}$; the maximum precipitation of this regime tends to occur in the evening (1800-0000 LST). Overall, the coastal regime is prominent in the following regions: the Maritime Continent and adjacent seas, the Indian subcontinent and the Bay of Bengal, northern Australia and the Arafura Sea, the vicinity of the coastline extending from Mexico to Ecuador, the west coast of equatorial Africa and the Gulf of New Guinea, and 
(a) PCs

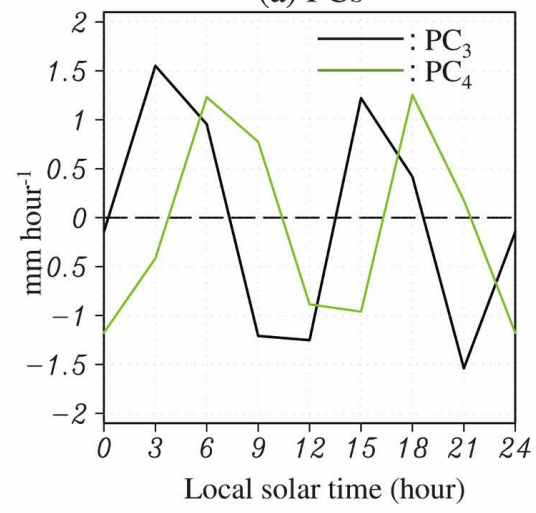

(b) 3B42 EOF3 (6\%)

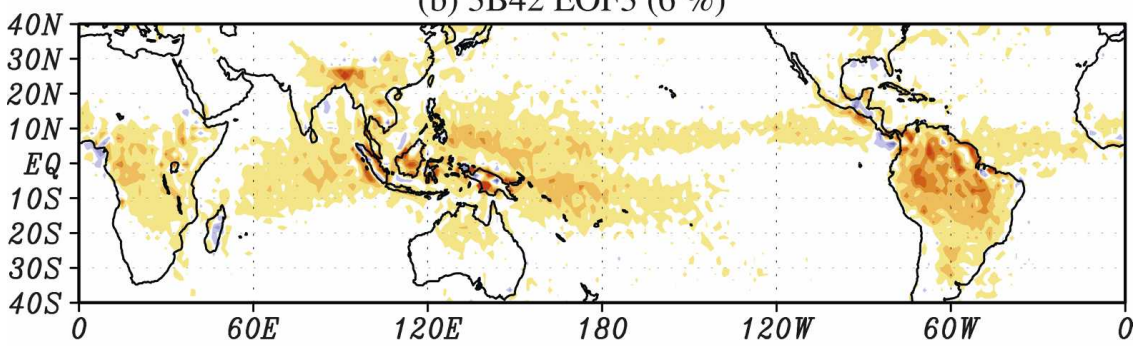

(c) $3 \mathrm{~B} 42 \mathrm{EOF} 4(4 \%)$

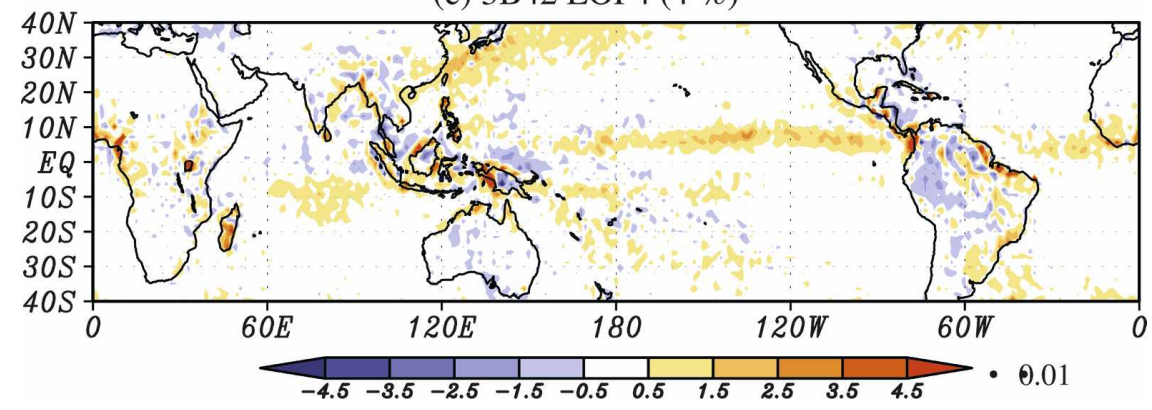

FIG. 6. Same as Fig. 4, but for $\mathrm{EOF}_{3}$ and $\mathrm{EOF}_{4}$ and without the eigenvalue spectrum. (a) Time series of the $\mathrm{PC}_{3}$ and $\mathrm{PC}_{4}$; horizontal distribution of (b) $\mathrm{EOF}_{3}$ and (c) $\mathrm{EOF}_{4}$. The horizontal resolution of the EOFs is $1.5^{\circ} \times 1.5^{\circ}$.

Northeast Brazil and the adjacent Atlantic Ocean. Note that the Great Plains appear to have a distribution of the EOFs that typically characterizes the landside coastal regime; however, it does not belong to it because of its geographical location. The reason why it shows a similar characteristic is that it has similar phase propagation characteristic, namely eastward phase propagation with time from the Rocky Mountains to the Great Plains (e.g., Tian et al. 2005) similar to the landside coastal regime. Thus, a new regime in which the behavior of diurnal precipitation is significantly affected by the presence of a mountain (topography) should probably be introduced into a complete description of the global diurnal precipitation. In this study, however, we focus on effects in the tropics.

As mentioned before, careful examination of the first two EOFs suggests the existence of phase propagation in the coastal regime. For instance, we find that the pattern of $\mathrm{EOF}_{1}$ on the island of Sumatra has a quartercycle phase difference from $\mathrm{EOF}_{2}$ off the west coast of the island. An afternoon peak occurs along the west coast of the island (1500-1800 LST), where $\mathrm{EOF}_{1}$ is almost dominant. But immediately off the west coast of the island, the diurnal cycle has a night peak $(\sim 2100$ LST), illustrated by a negative $\mathrm{EOF}_{2}$. Farther offshore, phase propagation can be deduced from the two EOFs in a similar way. A similar quarter-cycle phase difference can be seen clearly over the northeast coast of Brazil. As stated above, we will discuss this further in section 5 and show that this is a common feature over coastal regions.

Finally, we mention that $\mathrm{EOF}_{3}$ and $\mathrm{EOF}_{4}$ only ac- 
(a) 3B42 normalized by the DR EOF1 (38\%)

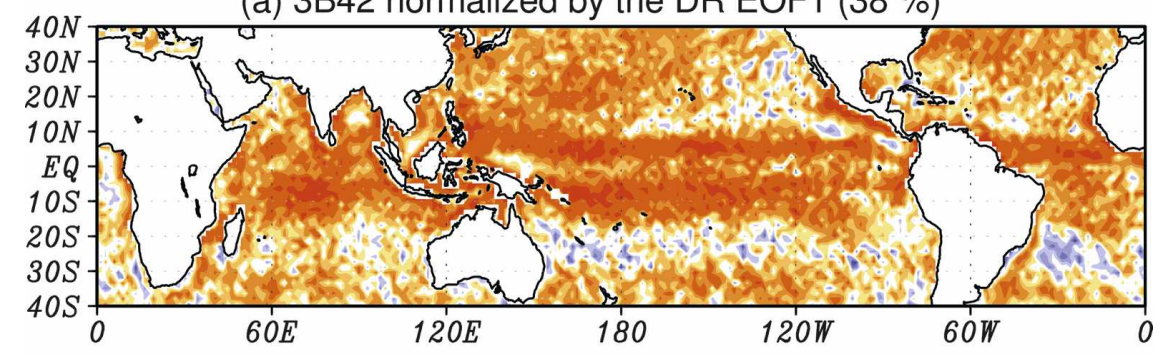

(b) 3B42 normalized by the DR EOF2 (20\%)

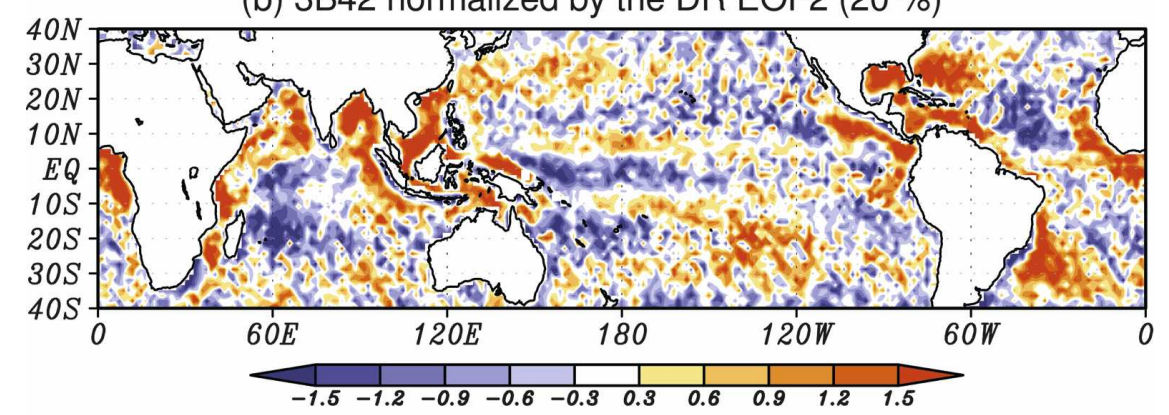

(c) PCs

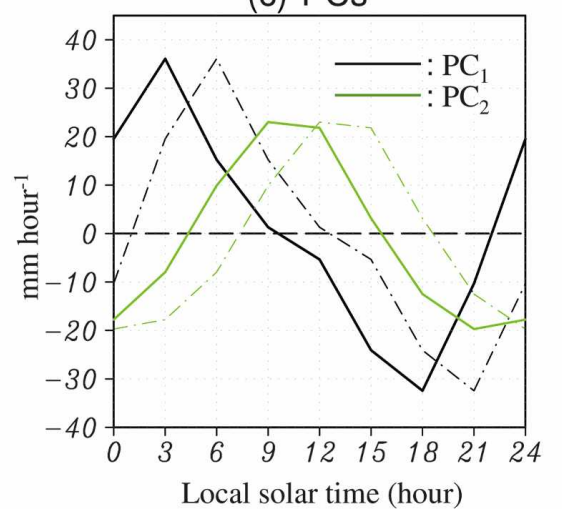

FIG. 7. As in Fig. 4, but with the data normalized by the DR and the EOF analysis was applied to only the ocean area. (a) Horizontal distribution of $\mathrm{EOF}_{1}$ and (b) $\mathrm{EOF}_{2}$. (c) Time series of the $\mathrm{PC}_{1}$ and $\mathrm{PC}_{2}$; solid lines are modified time series taking into account the phase difference between 3G68 and 3B42; and dashed-dotted lines are the actual time series. The horizontal resolution of the EOFs is $1.5^{\circ} \times 1.5^{\circ}$.

count for a small fraction of the diurnal variation. These two EOFs denote semidiurnal variation (Fig. 6a). EOF $_{3}$ (Fig. 6b), which has a single sign all over the tropics, is probably related to the semidiurnal tide (Haurwitz and Cowley 1973). The precipitation peak due to this component tends to occur at 0100-0200 LST and 1300-1400 LST based on 3G68. The amplitude basically follows the climatological annual precipitation (Fig. 1b), but the largest amplitude is in South America. $\mathrm{EOF}_{3}$ may enhance the diurnal precipitation over some regions, such as the inland of South America or coastal ocean areas that have precipitation maxima around 0200 or $1400 \mathrm{LST} . \mathrm{EOF}_{4}$ is noisier than $\mathrm{EOF}_{3}$. Its most significant signal may be found over the eastern Pacific along the ITCZ; by combining $\mathrm{EOF}_{3}$ and $\mathrm{EOF}_{4}$, a precipitation maximum occurs there in the nighttime (0100-0400 LST). Once again, the semidiurnal effects are marginal compared to the diurnal components of the EOFs.

\section{c. Diurnal precipitation over the land and over the ocean}

To elucidate diurnal precipitation in more detail, we now examine it over ocean and over land separately. In this subsection, the EOF analysis uses the data normalized by the local DR in order to better capture common features in propagation over ocean or land regardless of the amplitude.

Figure 7 shows the diurnal precipitation over ocean. 
(a) 3B42 normalized by the DR EOF1 (51\%)

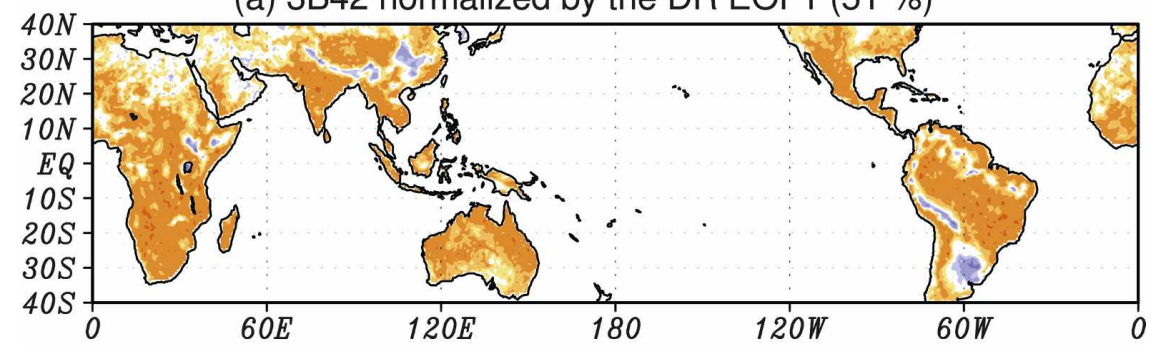

(b) 3B42 normalized by the DR EOF2 (21\%)

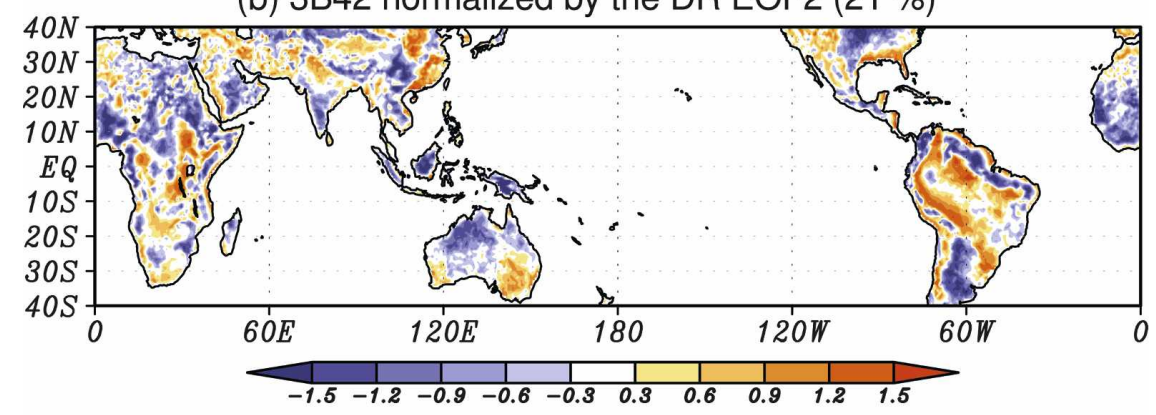

(c) PCs

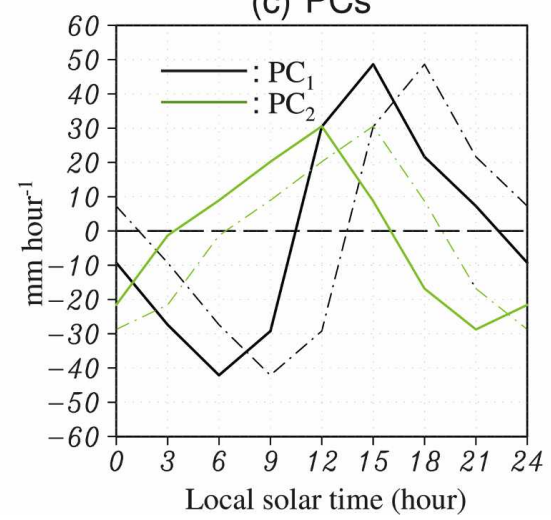

FIG. 8. Same as Fig. 7, but EOFs applied to land area only.

Although the sum of the first two EOFs is somewhat smaller than that without the normalization, it is still quite large, with values of $38 \%$ and $20 \%$, respectively. $\mathrm{EOF}_{1}$ shows a rather uniform feature, namely, almost all the regions have positive values and a nighttime peak (0300 LST) based on the modified PCs (Fig. 7c). On the other hand, $\mathrm{EOF}_{2}$ is more complex and shows the coastal-ocean regime clearly. The amplitude of $\mathrm{EOF}_{2}$ is large in the coastal-ocean regime, which includes seas adjacent to the Maritime Continent, the Arafura Sea, the Bay of Bengal, the area off the west coast of America extending from Mexico to Ecuador, the Caribbean Sea, the Arabian Sea, and the areas off the east coast of the Florida Peninsula, off the east coast of South America, off the west coast of equatorial Africa extending from Senegal to Angola, and off the east coast of South Africa extending from Mozambique to Somalia. These are typical regions where diurnal precipitation is highly influenced by the presence of a continent regardless of the amplitude of diurnal precipitation.

On the other hand, the open ocean in the tropics appears to have some typical features in terms of its peak time of precipitation. Deep convective regions are characterized by a large positive $\mathrm{EOF}_{1}$ and a small positive $\mathrm{EOF}_{2}$, suggesting that maximum precipitation tends to occur in the nighttime/early morning (03000600 LST). Between the ITCZ and SPCZ, there is another region along the equator that is characterized by weak positive $\mathrm{EOF}_{1}$ and moderate negative $\mathrm{EOF}_{2}$, suggesting that maximum precipitation there tends to occur earlier than in the deep convective region.

Figure 8 shows diurnal precipitation over land, for which about $72 \%$ of its variation can be explained by 
(a) S. Asia $(46,36 \%)$

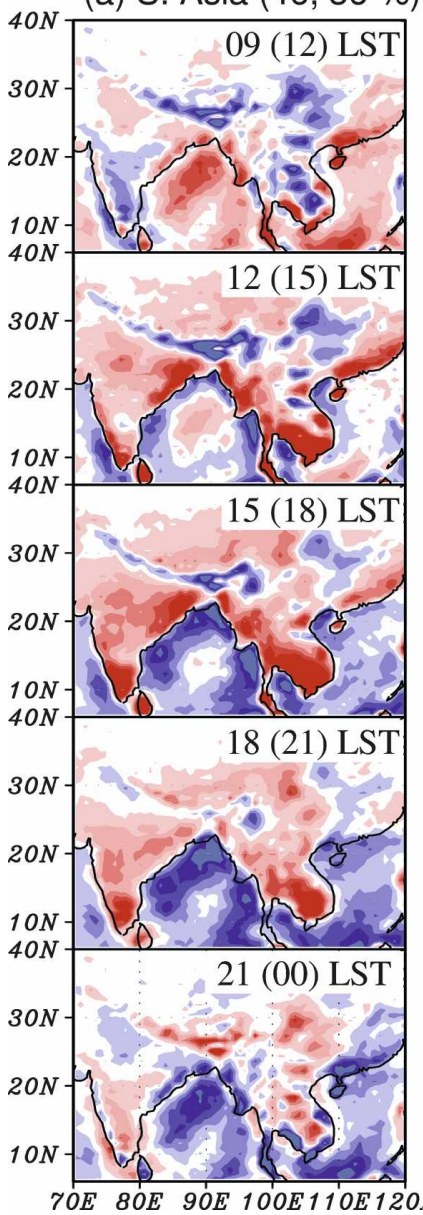

(b) America (44, $37 \%)$

(c) W. Africa $(50,36 \%)$

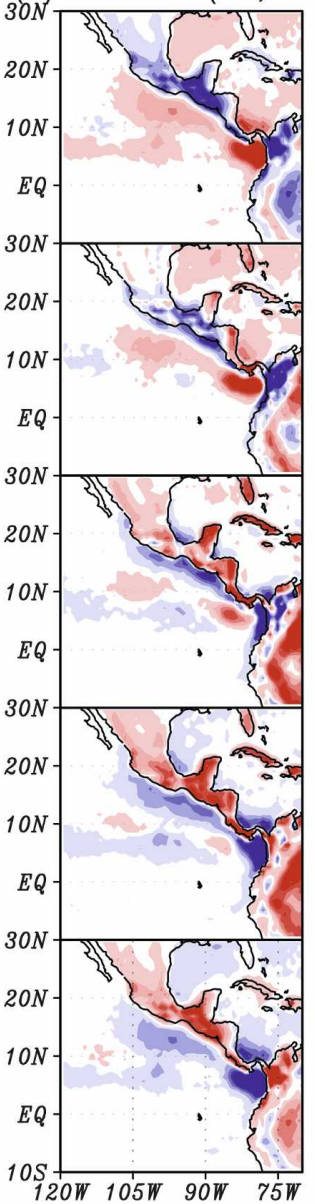

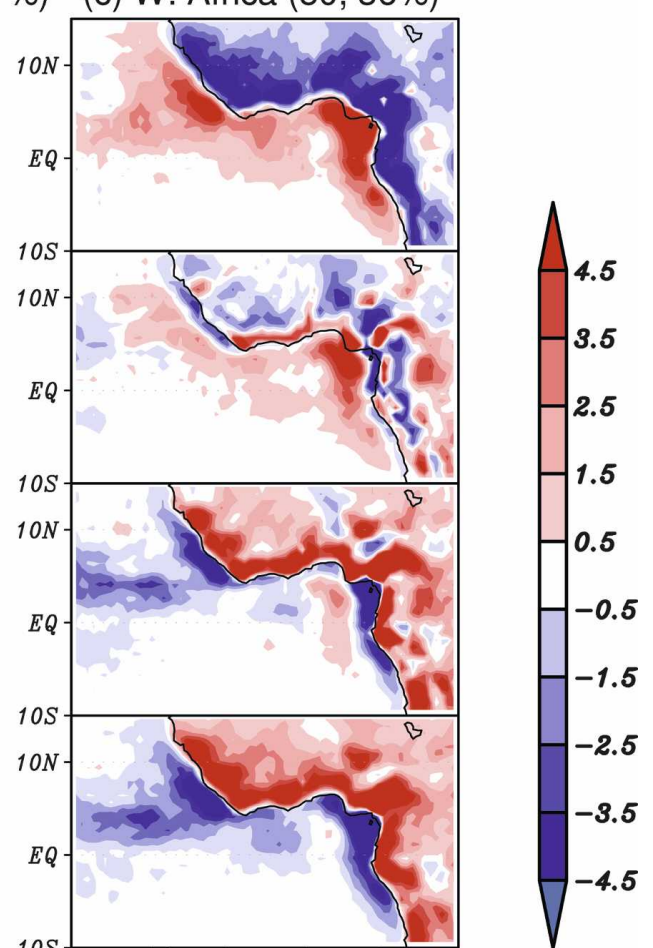

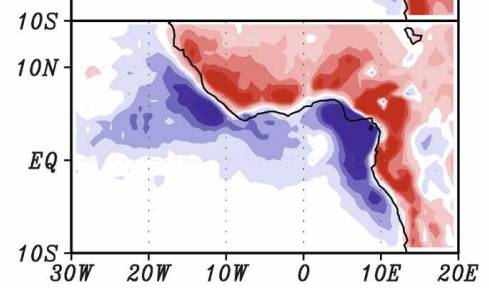

FIG. 9. Evolution of precipitation represented by the combination of $\mathrm{EEOF}_{1}$ and $\mathrm{EEOF}_{2}$ for the following regions: (a) South Asia, (b) Central America and northwest part of America, (c) West Africa, (d) Indonesia Maritime Continent, (e) South America, and (f) Madagascar. See the text for the complete description of the procedure. The corresponding modified LSTs are shown at the right corner of panels in (a) and (d). The horizontal resolution of the EEOFs is $0.75^{\circ} \times 0.75^{\circ}$.

$\mathrm{EOF}_{1}$ and $\mathrm{EOF}_{2} \cdot \mathrm{EOF}_{1}$ has a positive sign over almost all land areas (Fig. 8a) that have an afternoon (1500 LST) precipitation maximum (Fig. 8c). In contrast, $\mathrm{EOF}_{2}$ shows high spatial variation (Fig. 8b). The landside coastal regime could be characterized by the negative sign of $\mathrm{EOF}_{2}$, apart from some regions along the coast that have a positive sign resulting from earlier development of diurnal precipitation there. In the end, the following regions could be recognized as landside coastal regimes: the Maritime Continent, the Indian subcontinent, northern Australia, the vicinity of the coastline extending from Mexico to Ecuador, the west coast of equatorial Africa, and northeast Brazil. When combining the two $\mathrm{EOF}_{\mathrm{S}}$, the landside coastal regimes have a later precipitation maximum than inland areas that are considered to be free of the effect from the sea.

\section{Phase propagation in the coastal regime}

In this section, we examine the phase propagation of the diurnal precipitation in the coastal regime. The phase propagation was revealed by the EOF results in section 3a, and here we employ the extended EOF (EEOF) analysis to document it in more detail. The EEOF was performed on the 3B42 with two lags of $\pm 3 \mathrm{~h}$. The choice of the number of lags is subjective, but the current choice is good at representing the phase propagation (see below). Several regions belonging to the coastal regime, such as South Asia, Central America and the northwest part of South America, West Africa, the Maritime Continent, South America, and Madagascar (Figs. 9a-f, respectively) are selected because of their large diurnal range. Because the ma- 

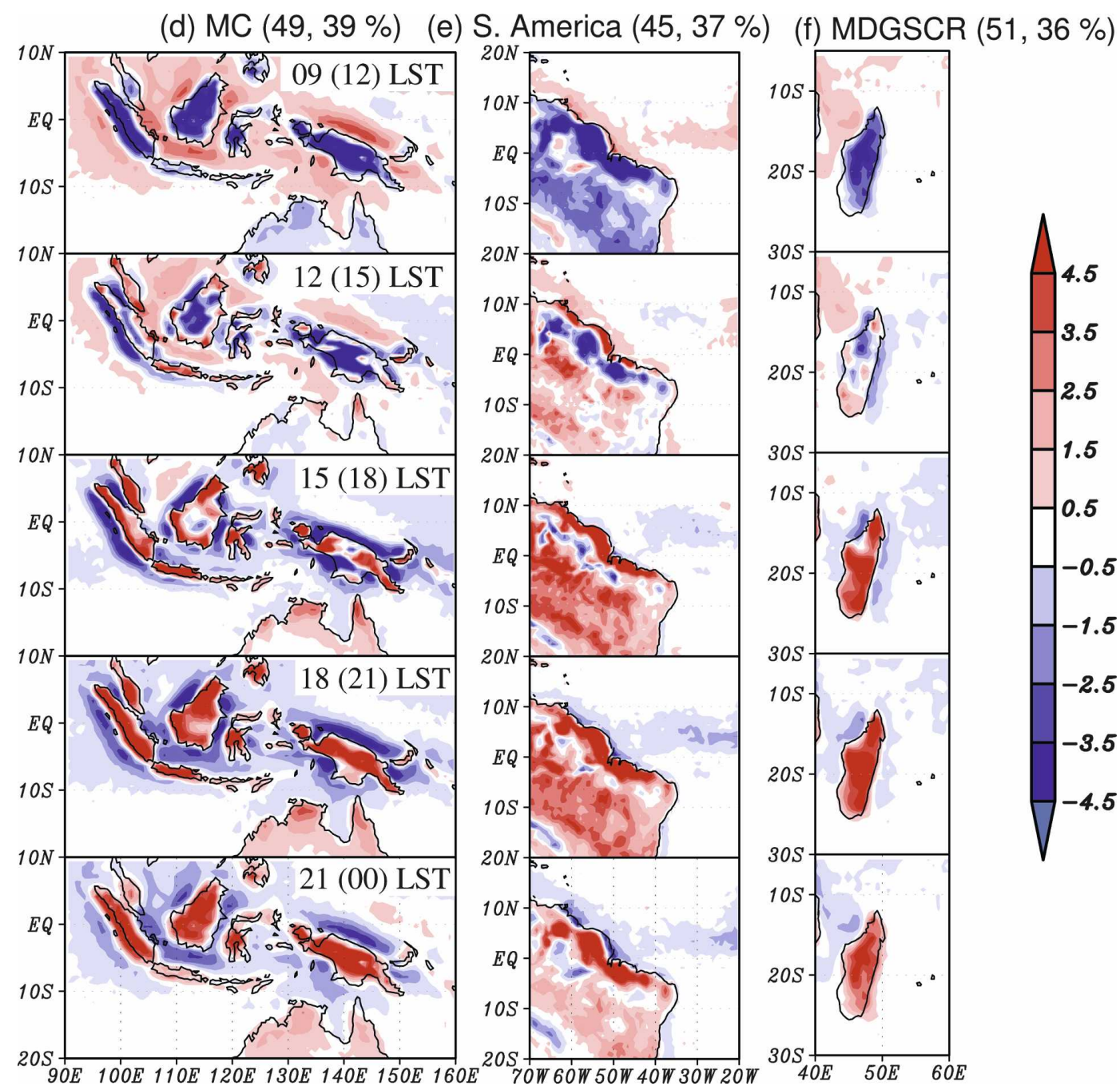

FIG. 9. (Continued)
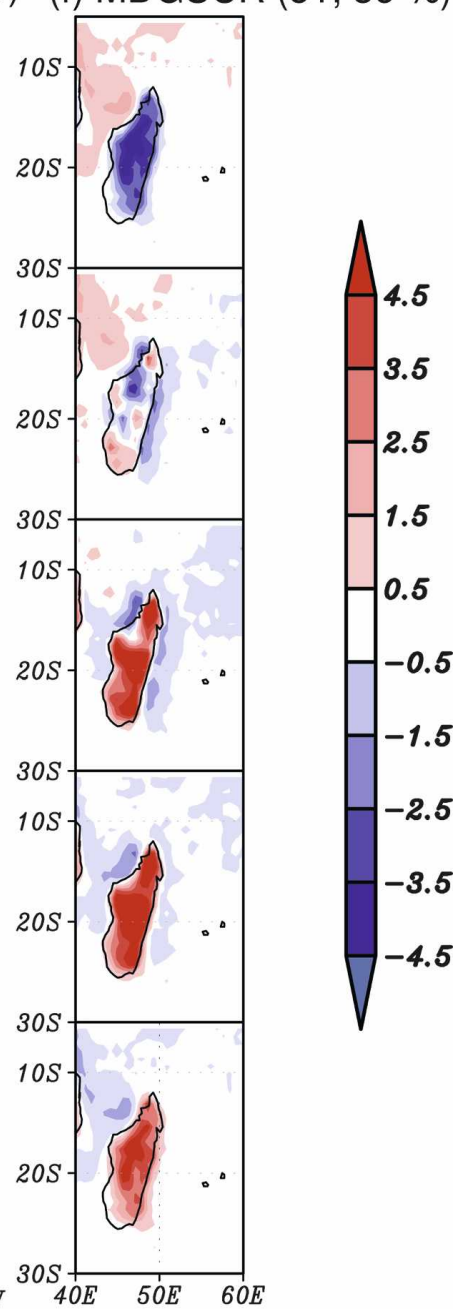

jority of the variation of the diurnal precipitation is accounted for by $\mathrm{EEOF}_{1}$ and $\mathrm{EEOF}_{2}(81 \%-88 \%)$, and $\mathrm{PC}_{1}$ and $\mathrm{PC}_{2}$ are in time quadrature, it is expected that $\mathrm{EEOF}_{1}(+3 \mathrm{~h})$ corresponds to $\mathrm{EEOF}_{2}(-3 \mathrm{~h})$, and similarly $\operatorname{EEOF}_{2}(+3 \mathrm{~h})$ corresponds to $\operatorname{EEOF}_{1}(-3 \mathrm{~h})$.

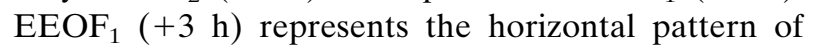
$\mathrm{EEOF}_{1}$ at lag $+3 \mathrm{~h}$. The constructed figure (Fig. 9) thus was obtained by combining three lags $(-3,0,+3 \mathrm{~h})$ of EEOF $_{1}$ and two lags $(0,+3 \mathrm{~h})$ of $\mathrm{EEOF}_{2}$, showing half a cycle of the diurnal precipitation. The counterpart half cycle from 2100 to 0900 in the modified time can be expressed by patterns with the signs opposite to Fig. 9 . Note that we will discuss the behavior of the diurnal cycle in the adjusted time frame.

The phase of precipitation propagates landward over coasts (Fig. 9). The precipitation anomaly starts to occur along the coastline around 0900-1200 LST. For example, weak positive precipitation anomalies begin to appear along the coastline of India and the Indochina Peninsula at 0900 LST (Fig. 9a). Then they expand and/ or move landward in the afternoon (1200-1500 LST). Precipitation reaches its mature stage around 1500 LST. Finally, the anomalies disappear farther inland at night around 2100 LST. A similar life cycle can be observed in other regions in the landside coastal regime although there is a slight difference in their time tables. Overall, the life cycle of the diurnal precipitation in the landside coastal regime is characterized by (i) the emergence of a precipitation anomaly along the coastline in the morning around 0900-1200 LST; (ii) landward expansion and/or phase propagation; (iii) complete development of precipitation around 1500 (Fig. 9a), 1800 (Figs. 9b, 9c, and 9f), or 2100 LST (Figs. 9d and 9f); and (iv) the disappearance of the precipitation anomaly inland.

On the other hand, precipitation anomalies propa- 


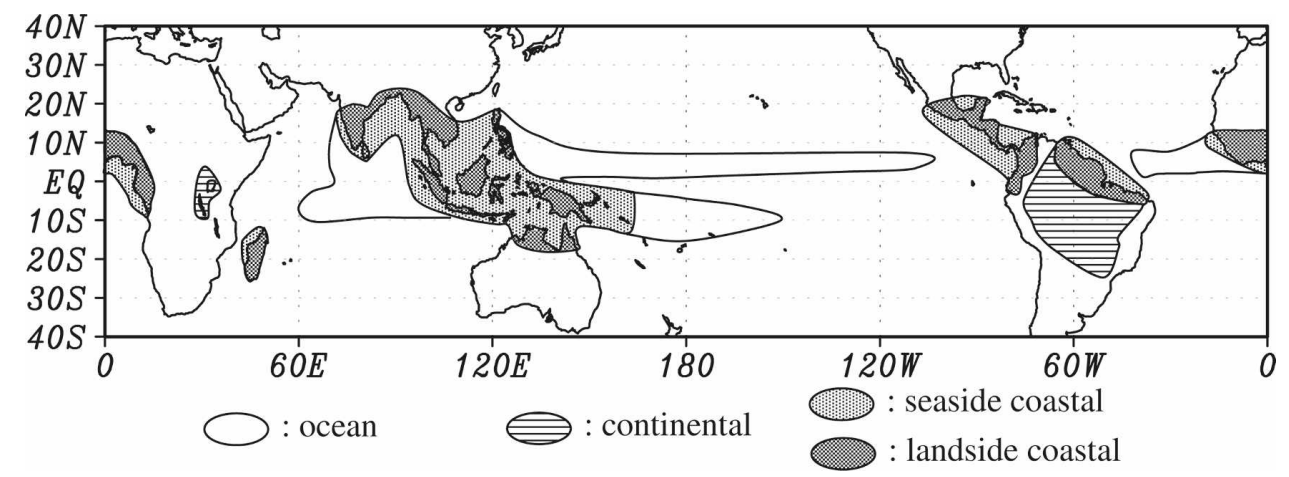

FIG. 10. Schematic diagram showing the global tropical diurnal precipitation regimes. Three regimes, namely oceanic, continental, and coastal regimes, are identified according to the amplitude, peak time, and phase propagation characteristics of the diurnal precipitation.

gate offshore over coastal ocean regions. For example, over the Bay of Bengal, they start to appear along the seaside coastline around 0000 LST and start to expand or move offshore (0300-0600 LST) with a peak around 0600 LST. Finally, they disappear over water around 1200-1500 LST. A similar life cycle can be observed in other regions in the seaside coastal regime. In summary, the life cycle of the diurnal precipitation in the seaside coastal regime is characterized by (i) the emergence of a precipitation anomaly along the seaside coastline around 0000 LST over most of the regions and around 1800 LST just off the west coast of Sumatra Island (Fig. 9d), (ii) offshore expansion and/or phase propagation, (iii) complete development of precipitation occurring from late evening to the noon of the next day (2100-1200 LST), and (iv) disappearance of the precipitation anomaly over water around 1200-1500 LST. Note that there is little evidence of phase propagation off the east coast of Brazil, which is consistent with the seaside coastal regime identification in Fig. 7.

\section{Conclusions and discussion}

In this study, we examined global diurnal precipitation in the tropics using the TRMM data. The results provide a metric for validation of numerical models as well as for organizing and broadening our knowledge. The TRMM provides one of the best precipitation estimates from space with a reasonably long period. The EOF analysis is found to be a powerful tool to describe global diurnal precipitation. One of the advantages of using EOF analysis is that it reduces the dimensions of component variations needed to describe most of the variation. In fact, the leading two EOFs alone can explain most of the variation of diurnal precipitation (89\% in 3B42). The other advantage of EOF analysis is the help it provides in interpreting the variability, pos- sibly into meaningful physical modes. In fact, $\mathrm{EOF}_{1}$ and $\mathrm{EOF}_{2}$ represent diurnal variation, and $\mathrm{EOF}_{3}$ and $\mathrm{EOF}_{4}$ represent semidiurnal variation (Fig. 6). Global diurnal precipitation is mainly accounted for by the large contribution $(89 \%)$ of the combination of $\mathrm{EOF}_{1}$ and $\mathrm{EOF}_{2}$. $\mathrm{EOF}_{1}$ represents a universal feature associated with land-sea contrast (Fig. 4). $\mathrm{EOF}_{2}$ represents geographical variation, which is critical for classifying all regions into several regimes. As a result, $\mathrm{EOF}_{1}$ and $\mathrm{EOF}_{2}$ alone capture essential features of diurnal precipitation in terms of peak time, amplitude, and phase propagation.

The combined use of two kinds of TRMM data increases the reliability of our results. Both datasets yield quite consistent spatial structures, but the patterns derived from 3B42 are more robust than those from 3G68. The 3G68 data yield a noisier pattern and the leading two EOF modes account for lower fractional variance. This is attributed to relatively poor spatial coverage of the data. The 3 G68 is a TMI-PR combined precipitation product and is more reliable in representing the diurnal phase of precipitation because it uses both passive and active microwave data to provide a better precipitation estimate. The 3B42, which uses passive microwave data and IR data, has two major limitations. First, the IR-based precipitation estimate tends to lag about 3-4 h behind the in situ rain gauge data (e.g., Houze and Betts 1981; Kubota and Nitta 2001), and second, the 3G68 TMI precipitation estimate lags TMIPR combined precipitation estimate by $1-2 \mathrm{~h}$.

We identified three regimes-the oceanic, the continental, and the coastal-according to amplitude, peak time, and phase propagation characteristics of diurnal precipitation. Figure 10 is a schematic summary. The oceanic region is characterized by moderate amplitude and an early morning peak (0600-0900 LST). The continental regime is characterized by large amplitude and little landward phase propagation with an afternoon 
peak (1500-1800 LST). The coastal regime displays more complex features in terms of its phase propagation. In the end, two subregimes can be recognized in the coastal regions. The seaside coastal regime is characterized by relatively large amplitude, offshore phase propagation with a peak occurring from late evening to noon of the next day (2100-1200 LST). The landside coastal regime is characterized by intense amplitude and a landward phase propagation with a peak occurring from noon to evening (1200-2100 LST).

One of the major contributions of this study is its demonstration that there are commonalities of propagation characteristics in the coastal regime. One precipitation anomaly starts to occur along the coastline from the morning to noon (0900-1200 LST), moves inland, and disappears in the evening (1800-2100 LST) in the landside coastal regime (Fig. 9). Another precipitation anomaly starts to occur along the coastline from the afternoon to midnight (1800-0000 LST), moves offshore, and disappears in the early afternoon (1200-1500 LST) in the seaside coastal regime. The phase speed in the landside and seaside coastal regime is roughly the same, on the order of $10 \mathrm{~m} \mathrm{~s}^{-1}$ (not shown). In previous studies, phase propagations were found between 10-20 $\mathrm{m} \mathrm{s}^{-1}$, for instance, $20 \mathrm{~m} \mathrm{~s}^{-1}$ over the Bay of Bengal (Yang and Slingo 2001), $10 \mathrm{~m} \mathrm{~s}^{-1}$ off the west coast of Sumatra Island (Mori et al. 2004), and $15 \mathrm{~m} \mathrm{~s}^{-1}$ over coastal land in Brazil.

The global diurnal precipitation as depicted by $\mathrm{EOF}_{1}$ and $\mathrm{EOF}_{2}$ can be used to measure the global models' performance in their simulation of the diurnal cycle in terms of pattern correlation coefficient and rms error. Because the spatial patterns derived from $3 \mathrm{~B} 42$ are more realistic and the diurnal phases $\left(\mathrm{PC}_{1}\right.$ and $\left.\mathrm{PC}_{2}\right)$ derived from $3 \mathrm{G} 68$ are more accurate, we recommend that the spatial patterns in Figs. $4 \mathrm{c}$ and $4 \mathrm{~d}$ and the principal components in Fig. $5 \mathrm{~b}$ be used to gauge the weather and climate models. For regional models, detailed propagation patterns depicted in the six panels of Fig. 9 can be used as a measure for evaluating the models' diurnal cycle.

What controls the diurnal phase propagations? The asymmetry between land breeze and sea breeze and the complicated distribution of terrain make the problem complex. In the landside coastal regime, sea breeze is thought to play an essential role in initiating and possibly maintaining propagating convection. Some studies (Kousky 1980; Cohen et al. 1995; Garreaud and Wallace 1997) suggested that convection propagates landward as a squall line initiated and possibly maintained by sea breeze over Northeast Brazil. Similar landward propagation of diurnal convection as a squall line can be seen over the Indochina Peninsula in a numerical simulation (Satomura 2000). When it comes to a small island, the sea-breeze front with a landward propagation covers the entire land (Saito et al. 2001). These characteristics are confirmed by the present study. For instance, a northwest-southeast precipitation band propagating landward can be seen over Northeast Brazil (Fig. 9e). Precipitation initiated along the coastline propagating landward can be seen in almost all continental lands in the Maritime Continent (Fig. 9d) and Madagascar (Fig. 9f). In addition, we may need to consider the effect of topography. A similar phase propagation feature was observed in the region between the Rocky Mountains and the Great Plains (e.g., Tian et al. 2004), which is far away from the ocean and thus free from the sea breeze. In the tropical regions to which we pay much attention in this study, the situation is more complex because of the mixture of the effects of sea breeze and topography over regions such as the Andes. In summary, the effect of the sea breeze is a prime candidate for explaining diurnal precipitation in most landside coastal regimes; however, topography could play an important role.

On the other hand, the mechanism controlling diurnal precipitation in the seaside coastal regime may be more complicated. Compared to sea breeze, land breeze is not as strong (Mapes et al. 2003) because of a weaker temperature difference between ocean and land at night. Thus, land breeze alone might not be enough to produce convergence, which induces precipitation. The land breeze combined with other factors, such as concavity of land (Neumann 1951) or monsoon mean flow (Houze et al. 1981), may produce offshore convergence but may not be able to explain offshore movement of precipitation and probably is not a major mechanism. In fact, the seaside coastal regime suggested by Fig. 7 can be seen over both ocean concavity and land concavity and both windward and leeward of monsoon mean flows. Gravity waves might be a more promising candidate for explaining initiating and maintaining convection in the seaside coastal regime (Yang and Slingo 2001). Gravity waves probably emanate from land convection (Zuidema 2003) and/or land topography (Mapes et al. 2003). Mapes et al. (2003) recently demonstrated in their numerical simulations that gravity waves emanated from the Andes by a diurnally varying heat source and complex processes; both turbulent heat flux convergence and a surface lifted by elevated terrain play an essential role in nocturnal convection propagating offshore in northwestern South America. Our observational evidence may support this hypothesis; in that not only land convection but also terrain contributes to generate offshore propagating nocturnal convection in the seaside coastal regime. The 
seaside coastal regime that is adjacent to mountainous land tends to show clearer offshore propagation characteristics. For instance, off the west coast of Sumatra Island or off the north coast of Papua New Guinea there is clearer offshore propagation of convection (Fig. 9a), and off the west coast of Northeast Brazil, where high mountains are absent, there is ambiguous offshore propagation of precipitation (Fig. 9e).

Mechanisms that produce a diurnal cycle in the ocean regime and the continental regime remain open to question. Because of the different heat capacity, the behaviors of the diurnal precipitation over the ocean and that over the continental regime are quite different. In the continental regime, diurnal precipitation seems to be driven by the direct thermodynamic response to solar heating through the interaction between land and atmosphere. However, we still need to clarify the detailed underlying process. In contrast, the ocean regime mechanism is less well understood. Many hypotheses have been proposed to explain an early morning precipitation peak, taking into account several processes such as radiative heating due to shortwave radiation, radiative cooling due to longwave radiation, associated circulation, associated change of static stability, and land-ocean processes (a detailed review regarding these mechanisms can be found in Yang and Smith 2006).

The characteristics mentioned above are not all affected by seasonal changes. The amplitude of diurnal precipitation, of course, is much affected by seasonal change; however, neither peak phase nor phase propagation is altered by season (Fig. 3). Thus, we do not need to pay much attention to seasonal dependence except when the amplitude matters.

The observational evidence obtained here provides critical information for validating the physical parameterizations in numerical models. By comparing the observational evidence and numerical simulations or by comparing numerical simulations of two regions that should have the same diurnal characteristics implied by the observational evidence, we could identify which process is essential and which process is missing in numerical simulations. Since many numerical models have difficulty in reproducing observed diurnal cycles (Randall et al. 1991; Lin et al. 2000; Yang and Slingo 2001; Dai and Trenberth 2004; Tian et al. 2004), there remains much work to be done in continuing improvements of the representation of physical processes in the numerical models.

Acknowledgments. This research was supported by NSF Grant ATM-0647995. Additional support was provided by the Japan Agency for Marine-Earth Science and Technology (JAMSTEC), by NASA Grant NNX07AG53G through their sponsorship of research activities at the International Pacific Research Cener. We thank Dr. Kubota for his comments. We also thank Dr. Baijun Tian, one of the reviewers, and an anonymous reviewer for their helpful comments. We also give thanks to Ms. Di Henderson for her editorial work. The data used in this study were processed by the TRMM Science Data and Information System (TSDIS) and the TRMM Office, and are archived and distributed by the Goddard Distributed Active Archive Center. TRMM is an international project jointly sponsored by the Japan National Space Development Agency (NASDA) and the U.S. National Aeronautics and Space Administration (NASA) Office of Earth Sciences.

\section{REFERENCES}

Albright, M. D., D. R. Mock, E. E. Recker, and R. J. Reed, 1981: A diagnostic study of the diurnal rainfall variation in the GATE B-scale area. J. Atmos. Sci., 38, 1429-1445.

_ , E. E. Recker, R. J. Reed, and R. Dang, 1985: The diurnal variation of deep convection and inferred precipitation in the central tropical Pacific during January-February 1979. Mon. Wea. Rev., 113, 1663-1680.

Andersson, T., 1970: The diurnal variation of precipitation frequency over Weather Ship M. J. Appl. Meteor., 9, 17-19.

Arkin, P. A., and B. N. Meisner, 1987: The relationship between large-scale convective rainfall and cold cloud over the western hemisphere during 1982-84. Mon. Wea. Rev., 115, 51-74.

Augustine, J. A., 1984: The diurnal variation of large-scale inferred rainfall over the tropical Pacific Ocean during August 1979. Mon. Wea. Rev., 112, 1745-1751.

Bowman, K. P., J. C. Collier, G. R. North, Q. Wu, E. Ha, and J. Hardin, 2005: Diurnal cycle of tropical precipitation in Tropical Rainfall Measuring Mission (TRMM) satellite and ocean buoy rain gauge data. J. Geophys. Res., 110, D21104, doi:10.1029/2005JD005763.

Chang, A. T. C., L. S. Chiu, and G. Yang, 1995: Diurnal cycle of oceanic precipitation from SSM/I data. Mon. Wea. Rev., 123, 3371-3380.

Cohen, J. C. P., M. Dias, and C. A. Nobre, 1995: Environmental conditions associated with Amazonian squall lines: A case study. Mon. Wea. Rev., 123, 3163-3174.

Cook, A. W., 1939: The diurnal variation of summer rainfall at Denver. Mon. Wea. Rev., 67, 95-98.

Dai, A., and K. E. Trenberth, 2004: The diurnal cycle and its depiction in the Community Climate System Model. J. Climate, 17, 930-951.

Garreaud, R. D., and J. M. Wallace, 1997: The diurnal march of convective cloudiness over the Americas. Mon. Wea. Rev., 125, 3157-3171.

Gray, W. M., and R. W. Jacobson Jr., 1977: Diurnal variation of deep cumulus convection. Mon. Wea. Rev., 105, 1171-1188.

Hamilton, K., 1981: A note on the observed diurnal and semidiurnal rainfall variations. J. Geophys. Res., 86, 12122 12126.

Haurwitz, B., and A. D. Cowley, 1973: The diurnal and semidiurnal barometric oscillations, global distribution, and annual variation. Pure Appl. Geophys., 102, 193-222. 
Hendon, H. H., and K. Woodberry, 1993: The diurnal cycle of tropical convection. J. Geophys. Res., 98, 16 623-16 637.

Houze, R. A., Jr., and A. K. Betts, 1981: Convection in GATE. Rev. Geophys. Space Phys., 19, 541-576.

, S. G. Geotis, F. D. Marks Jr., and A. K. West, 1981: Winter monsoon convection in the vicinity of north Borneo. Part I: Structure and time-variation of the clouds and precipitation. Mon. Wea. Rev., 109, 1595-1614.

Huffman, G. J., and Coauthors, 2007: The TRMM Multisatellite Precipitation Analysis (TMPA): Quasi-global, multiyear, combined-sensor precipitation estimates at fine scales. $\mathrm{J}$. $\mathrm{Hy}$ drometeor., 8, 38-55.

Janowiak, J. E., P. A. Arkin, and M. Morrissey, 1994: An examination of the diurnal cycle in oceanic tropical rainfall using satellite and in situ data. Mon. Wea. Rev., 122, 2296-2311.

Jiang, X., N.-C. Lau, and S. A. Klein, 2006: Role of eastward propagating convection systems in the diurnal cycle and seasonal mean of summertime rainfall over the U.S. Great Plains. Geophys. Res. Lett., 33, L19809, doi:10.1029/ 2006GL027022.

Knutson, T. R., and K. M. Weickmann, 1987: 30-60 day atmospheric oscillations: Composite life cycles of convection and circulation anomalies. Mon. Wea. Rev., 115, 1407-1436.

Kousky, V. E., 1980: Diurnal rainfall variation in Northeast Brazil. Mon. Wea. Rev., 108, 488-498.

Kraus, E. B., 1963: The diurnal precipitation change over the sea. J. Atmos. Sci., 20, 551-556.

Kubota, H., and T. Nitta, 2001: Diurnal variations of tropical convection observed during the TOGA-COARE. J. Meteor. Soc. Japan, 79, 815-830.

Kummerow, C., and Coauthors, 2000: The status of the Tropical Rainfall Measuring Mission (TRMM) after two years in orbit. J. Appl. Meteor., 39, 1965-1982.

Lin, X., D. A. Randall, and L. D. Fowler, 2000: Diurnal variability of the hydrologic cycle and radiative fluxes: Comparisons between observations and a GCM. J. Climate, 13, 4159-4179.

Lorenz, E. N., 1956: Empirical orthogonal functions and statistical weather prediction. Statistical Forecasting Project Scientific Rep. 1, Department of Meteorology, Massachusetts Institute of Technology, $49 \mathrm{pp}$.

Mapes, B. E., T. T. Warner, and M. Xu, 2003: Diurnal patterns of rainfall in northwestern South America. Part III: Diurnal gravity waves and nocturnal convection offshore. Mon. Wea. Rev., 131, 830-844.

McGarry, M. M., and R. J. Reed, 1978: Diurnal variations in convective activity and precipitation during phases II and III of GATE. Mon. Wea. Rev., 106, 101-113.

Mori, S., and Coauthors, 2004: Diurnal land-sea rainfall peak migration over Sumatera Island, Indonesian Maritime Continent, observed by TRMM satellite and intensive rawinsonde soundings. Mon. Wea. Rev., 132, 2021-2039.

Negri, A. J., T. L. Bell, and L. Xu, 2002: Sampling of the diurnal cycle of precipitation using TRMM. J. Atmos. Oceanic Technol., 19, 1333-1344.

Nesbitt, S. W., and E. J. Zipser, 2003: The diurnal cycle of rainfall and convective intensity according to three years of TRMM measurements. J. Climate, 16, 1456-1475.

Neumann, J., 1951: Land breezes and nocturnal thunderstorms. J. Meteor., 8, 60-67.

North, G. R., T. L. Bell, R. F. Cahalan, and F. J. Moeng, 1982: Sampling errors in the estimation of empirical orthogonal functions. Mon. Wea. Rev., 110, 699-706.
Ohsawa, T., H. Ueda, T. Hayashi, A. Watanabe, and J. Matsumoto, 2001: Diurnal variations of convective activity and rainfall in tropical Asia. J. Meteor. Soc. Japan, 79, 333-352.

Ramage, C. S., 1964: Monsoon Meteorology. Academic Press, 296 pp.

Randall, D. A., Harshvardhan, and D. A. Dazlich, 1991: Diurnal variability of the hydrologic cycle in a general circulation model. J. Atmos. Sci., 48, 40-62.

Ray, C. L., 1928: Diurnal variation of rainfall at San Juan, P. R. Mon. Wea. Rev., 56, 140-141.

Reed, R. J., and K. D. Jaffe, 1981: Diurnal variation of summer convection over West Africa and the tropical eastern Atlantic during 1974 and 1978. Mon. Wea. Rev., 109, 2527-2534.

Saito, K., T. Keenan, G. Holland, and K. Puri, 2001: Numerical simulation of the diurnal evolution of tropical island convection over the Maritime Continent. Mon. Wea. Rev., 129, 378400

Salby, M. L., H. H. Hendon, K. Woodberry, and K. Tanaka, 1991: Analysis of global cloud imagery from multiple satellites. Bull. Amer. Meteor. Soc., 72, 467-480.

Satomura, T., 2000: Diurnal variation of precipitation over the Indo-China Peninsula: Two-dimensional numerical simulation. J. Meteor. Soc. Japan, 78, 461-475.

Simpson, J., C. Kummerow, W. K. Tao, and R. F. Adler, 1996: On the Tropical Rainfall Measuring Mission (TRMM). Meteor. Atmos. Phys., 60, 19-36.

Smith, G. L., and D. A. Rutan, 2003: The diurnal cycle of outgoing longwave radiation from Earth Radiation Budget Experiment measurements. J. Atmos. Sci., 60, 1529-1542.

Sorooshian, S., X. Gao, K. Hsu, R. A. Maddox, Y. Hong, H. V. Gupta, and B. Imam, 2002: Diurnal variability of tropical rainfall retrieved from combined GOES and TRMM satellite information. J. Climate, 15, 983-1001.

Sui, C.-H., K.-M. Lau, Y. N. Takayabu, and D. A. Short, 1997: Diurnal variations in tropical oceanic cumulus convection during TOGA COARE. J. Atmos. Sci., 54, 639-655.

Takayabu, Y. N., 2002: Spectral representation of rain profiles and diurnal variations observed with TRMM PR over the equatorial area. Geophys. Res. Lett., 29, 1584, doi:10.1029/ 2001GL014113.

Thompson, D. W. J., and J. M. Wallace, 1998: The Arctic Oscillation signature in the wintertime geopotential height and temperature fields. Geophys. Res. Lett., 25, 1297-1300.

Tian, B., B. J. Soden, and X. Wu, 2004: Diurnal cycle of convection, clouds, and water vapor in the tropical upper troposphere: Satellites versus a general circulation model. J. Geophys. Res., 109, D10101, doi:10.1029/2003JD004117.

, I. M. Held, N.-C. Lau, and B. J. Soden, 2005: Diurnal cycle of summertime deep convection over North America: A satellite perspective. J. Geophys. Res., 110, D08108, doi:10.1029/ 2004JD005275.

Wallace, J. M., 1975: Diurnal variations in precipitation and thunderstorm frequency over the conterminous United States. Mon. Wea. Rev., 103, 406-419.

Yang, G.-Y., and J. Slingo, 2001: The diurnal cycle in the tropics. Mon. Wea. Rev., 129, 784-801.

Yang, S., and E. A. Smith, 2006: Mechanisms for diurnal variability of global tropical rainfall observed from TRMM. J. Climate, 19, 5190-5226.

Zuidema, P., 2003: Convective clouds over the Bay of Bengal. Mon. Wea. Rev., 131, 780-798. 